\title{
Sustainable safety evaluation of roads network in case of extreme weather events
}

\author{
Alessandro Pucci ${ }^{1}$, Mario Lucio Puppio ${ }^{2}$, Linda Giresini $^{2}$, José Matos ${ }^{1}$, Hélder Sousa ${ }^{1}$ and \\ Mauro $\mathrm{Sassu}^{3}$ \\ ${ }^{1}$ Universidade do Minho, Department of Civil Engineering, Campus de Azurém, 4800-058, \\ Guimarães, Portugal. \\ ${ }^{2}$ University of Pisa, Department of Energy, System, Territory and Construction Engineering \\ (DESTeC), Largo Lucio Lazzarino 1. 56120 Pisa, Italy. \\ ${ }^{3}$ University of Cagliari, Department of Civil, Environmental Engineering, and Architecture \\ (DICAAR), Via Marengo 2, 09120 Cagliari, Italy.
}

\begin{abstract}
Recent failures in road networks highlight their vulnerability towards natural hazards, particularly to extreme weather events. This paper proposes a method to evaluate the safety of road networks in case of collapse of one or more bridges. In addition, relevant consequences in terms of safety of human life, direct and indirect cost are crucial aspects to consider. The framework described here is based on the knowledge of road and river network, of the individual bridges and of the traffic data. However, this approach can be generalized in case of interruption of road network due to other causes. An algorithm has been developed to extract traffic data from Google and elaborate it throughout a procedure based on the application of the USA Highway Capacity Manual. This consents to have a quantitative definition of the road traffic directly from the users and to get updated traffic data. The maps are processed throughout a GIS software and, thanks to the application of a routing algorithm and proper constraints, it is possible to evaluate the effects of the interruption of one or more bridges. The consequences are evaluated in terms of drivers' delay and time cost. This provides useful information about priority of intervention with the aim of proposing to stakeholders a suitable instrument for disaster prevention and management.
\end{abstract}

Key words. Safety of roads network, bridges of reduced span, disaster management, Urban Planning, GIS, Traffic Database, Costs Analysis.

\section{Introduction}

Current climate changes are modifying duration, frequency and intensity of rainstorms with negative consequences on transport infrastructures. The delay or the missed aid, increases the number of fatalities and produces economic losses related to the productive activities. Furthermore, the vulnerability of roadways to climate events is also a problem for the 
competitivity with other countries. Hence, a damaged infrastructure on a road has a remarkable impact either in direct and indirect costs.

\section{State of the art}

Recent failures highlighting the vulnerability of primary and secondary road networks. Particularly, the bridges of reduced span (BRS) are prone to collapse in case of rainstorms [1]. The consequences of BRS failure can be direct or indirect: i.e. structural damaging and repair expenses are direct costs, while travel time increase and driven path lengthening are indirect costs [3]. The latter are particularly influenced by the users conduct [4]. To study the effects of a street interruption, the reactions of the drivers should be considered: (i) choice of an alternative path; (ii) change in the mode of transport; (iii) change of destination; (iv) waive the journey. Although the preferred option is to maintain the usual vehicle, even lengthening the path, when delays become unacceptable an intermodal transport is necessary [4].

\subsection{Consequences of a road interruption: the Morandi's Bridge in Genoa}

An enlighten example is the collapse of the A10 highway bridge on the Polcevera river in Genoa [5]. Designed by Eng. Morandi and placed into service in 1967, this bridge was already, at the beginning, a strategic infrastructure, due to the high volume of traffic [6]. Despite the redundancy of alternative roads, the collapse of Morandi's bridge generates great congestions in the traffic. This leads to direct and indirect damages. The total economic loss for freight companies is approximately of $2.000 .000,00 €$ per day [7]; if current trends continue, the losses for these companies are likely to arise to a billion Euros at the end of Dec. 2019 [8]. The cited costs are referred only to the freight transport, but there is also a damage to the society (that is also relevant). Indeed, the railway company increased the number of trains to allow workers to reach their workplaces [9]. This testifies as the waiting time in road network becomes unsustainable after the bridge collapse and summarise some of the abovementioned aspects.

\section{Method}

The objective of this research is the sustainable assessment of road safety following the collapse of one or more elements at risk. Recent events highlighted bridges as one of the most vulnerable elements of a road network [2, 3, 15, 16, 17]. The proposed method investigates the consequences of floods on road network (identifying bridges as weak elements), but can be extended to other hazards, such as earthquakes, volcano eruptions, by correcting some input variables. To assess the road network' safety, considering only bridges crossing rivers, the following data are required: (1) a data management and processing system; (2) a road network; (3) a hydraulic network; (4) the bridges position and characteristics; (5) traffic data. The first point (1) is needed to carry out analytic operations on maps; in this study the open source software QGIS was used. Choosing the appropriate road map database (2) is another essential requirement. Nowadays, there are several maps, both closed and open source. Besides the economic sustainability, the choice must be performed also on completeness and accuracy of the map. The sources include the following: (a) the INSPIRE database; and (b) the OpenStreetMap project (OSM) [13]. Regarding (a), the European Geoportal is the reference point where all the official maps created by the local governments are listed. Concerning (b), the reliability of OSM data is left to a comparison with official ones. In some areas, it has been found errors within this 
assessment, although the results differ considerably only for the motorways access ramps [14]. Therefore, if an official map is missing, it is recommended to overlay the non-official map layer with updated satellite images. About (3), the same which applies to (2), but changing the dataset if the vulnerable elements are not bridges. The requirement (4) can be obtained from a local government database, which reports the risk associated to each bridge in case of a flood; otherwise it is possible to intersect the layers of roads and rivers in QGIS, and then proceed to a survey campaign to assess the hydraulic risk linked to bridges. The (5) is the hardest dataset to be found, since it is often owned by a private company, which usually only releases it under payment. The knowledge of traffic volumes is of the utmost importance to evaluate the consequences of a road interruption. The OpenTransportMap (OTM) project is a database where the traffic volume is obtained through two kind of information: resident population statistics and street hierarchy. To validate the dataset, a comparison was made between OTM and official traffic volume provided by ANAS in the Province of Massa - Carrara (MS) and La Spezia (SP), Italy. The results are shown in Table 1.

Table 1. Traffic Volume comparison (OTM - ANAS).

\begin{tabular}{|c|c|c|}
\hline MS and SP & \multicolumn{2}{|c|}{ Average Daily Traffic (ADT), vehicles/day } \\
\hline Road & OTM (ott.2015) & ANAS (nov.2015) \\
\hline SS1 & 4152 & 20649 \\
\hline SS62 & 1702 & 10795 \\
\hline SS63 & 5081 & 3884 \\
\hline SS62 & 308 & 8473 \\
\hline
\end{tabular}

According to data, the volume of traffic from OTM is away from the one physically recorded by ANAS, nor can be found a relationship between the two datasets. Therefore, is not recommended to use OTM for traffic volumes. But on the other side, the values from ANAS are just few compared to the road network extension. Hence, the Average Daily Traffic is still unknown. Therefore, an innovative method for calculating this parameter will be proposed in this work.

\subsection{Analysis with missing traffic data}

Although the traffic volume is hard to be found, it is possible to determine it trough the knowledge of street's capacity and the road's Level of Service. The capacity of a road, measured in vehicles per hour, is defined as the traffic flow that most likely will not be exceeded [15]. Among the methods for calculating this parameter, the following were considered: (1) capacity through Highway Capacity Manual (HCM) formulas; (2) capacity obtained from OTM project (note that capacity is not the traffic volume abovementioned). The Level of Service (LOS), it represents a qualitative measure of traffic conditions; it describes the vehicle's flow in terms of comfort and travel time. For each road segment can be defined six LOS, named with letters from A to F. A is the best operating condition, $\mathrm{F}$ the worst [16]. Usually, the LOS is the output parameter when the traffic performance of a road is assessed. In this research is taken as an input parameter.

Then, the average traffic speed for a given LOS must be appraised. Each Level of Service has a range of speed, so the mean value of every interval is assumed. Furthermore, the LOS depends also on the street's class which the road belongs to. This implies a division of the transportation system into subsystems as freeways, rural highways and urban streets. In the arterial network, streets are classified in four categories, according to the following criterions: (1) access density; (2) arterial type (e.g. multilane, undivided, one-way, twoway); (3) parking (no, some, significant); (4) separate left-turn lanes; (5) number of signals 
per km; (6) speed limit; (7) pedestrian activity; (8) roadside density development. Once the street is classified, some typical Free-Flow Speed (FFS) values are proposed, and the mean speed for a given LOS can be determined. The next step is to quantify the segment's capacity: this could be done through HCM or OTM. If the latter is chosen, it is automatically knowable the length of all segments, since OTM is provided in vector maps. This allows to calculate either the link traversal time corresponding to LOS and the one at Free-Flow Speed. See the following (1) and (2).

$$
\begin{aligned}
& R=L / S_{L O S} \\
& R_{0}=L / F F S
\end{aligned}
$$

Where, $\mathrm{L}$ is the segment length and $\mathrm{S}_{\mathrm{LOS}}$ is the mean speed for the given LOS. The traffic volume, in vehicles per hour, is named $\mathrm{X}$ and defined in (3)

$$
X=v / c
$$

Where, $v$ is the volume of traffic demand in veh/h and $\mathrm{c}$ is the street's capacity in $\mathrm{veh} / \mathrm{h}$. Through the HCM equation for the link traversal time computation, it is possible to achieve the volume, with (4)

$$
v=f\left(c, L, S_{L O S}, F F S\right)
$$

The volume found with this method refers to a value of speed estimated through the knowledge of LOS, by the use of a software called Traffic Tool, specifically designed and described below. The workflow is shown in Figure 1.

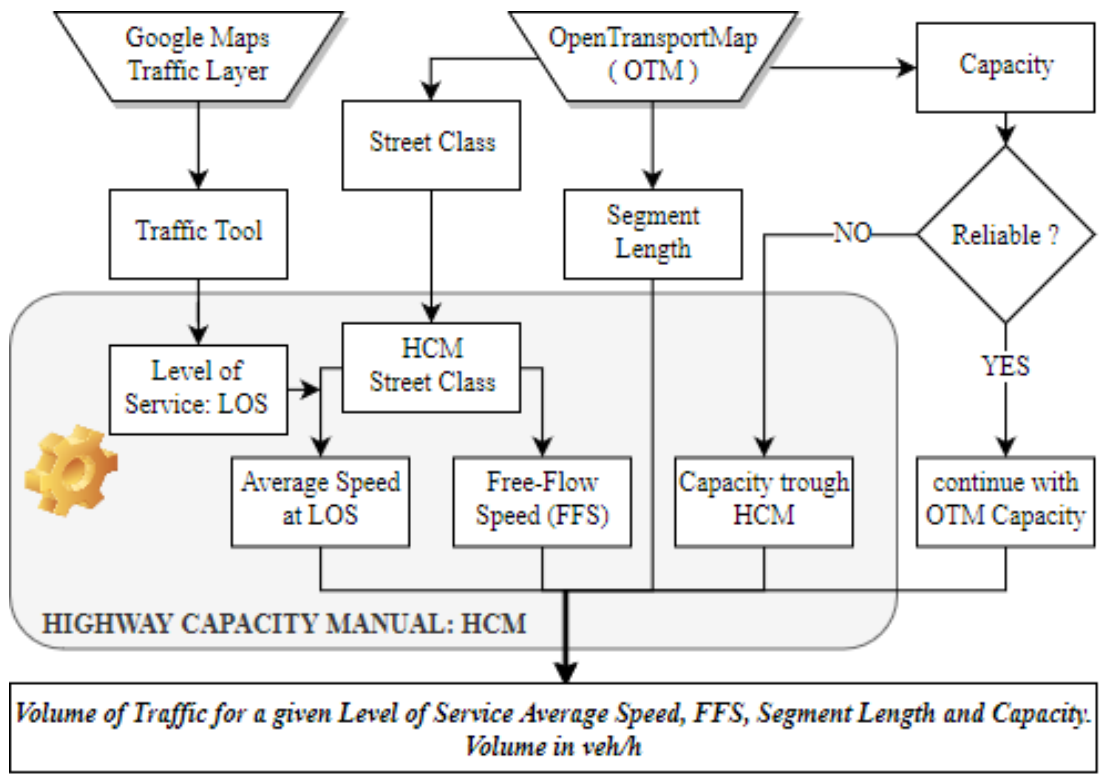

Fig. 1. Workflow to determine the volume of traffic. 


\subsection{Traffic Tool}

The program was developed to obtain the Level of Service for a given road segment, through Google Maps. The Traffic Tool is a script with graphical interface, in IJ1 language (C variant). This application uses ImageJ to run[17]. Indeed, the Traffic Tool uses ImageJ to create a mosaic of images obtained through an automatic procedure that simply involves the print screen. When the algorithm starts, it executes the steps shown in the flowchart of Figure 2. The calibration parameter (4) indicates how many pixels is one meter on the map. It was found through a linear interpolation of several tests. The method uses the distancemeasuring tool in Google Maps and the pixel-count tool in ImageJ. Using crop command in ImageJ (5), was obtained a 707x707 pixels image (6) from a screen of 1440x900. By simple formulae, (7), (8), (9), (10) were calculated. The conversion from kilometric coordinates to geographical coordinates in decimal degrees, was performed according to the procedure reported in [18]. This step was necessary since Google Maps uses the EPSG:3857. The URL of images are generated within the cycles indicated with (12) for Latitude and (13) for Longitude. Through the Tool it is possible to get the real time or typical traffic. In the latter case, further actions are required by the user. Once the qualitative traffic conditions have been found, the volume of cars per hour (for a given segment) is obtained. This last step is performed along the abovementioned method shown in Figure 1.

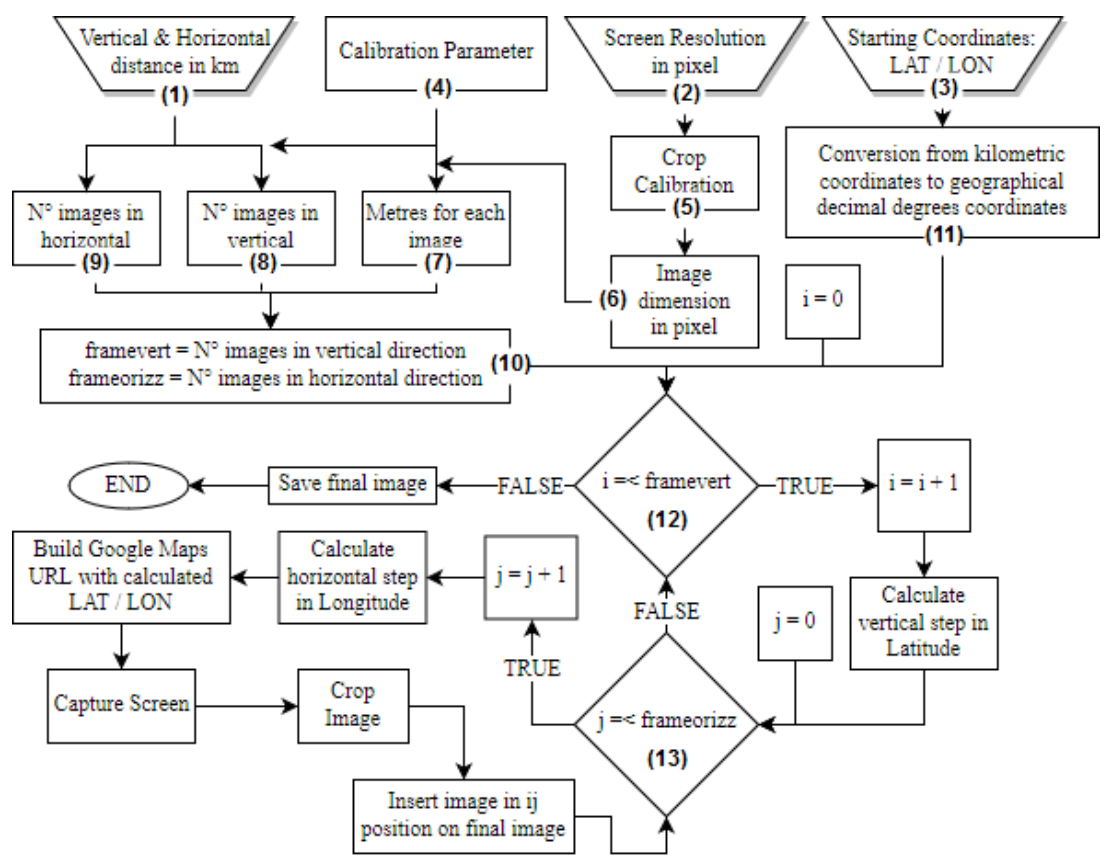

Fig. 2. Traffic Tool algorithm flowchart.

\subsection{Collapse scenarios}

The collapse scenarios are introduced by a four-input model. With reference to Figure 3 , the method is based on the following assumption: the collapse of vulnerable elements (2), occurs due to an extreme weather event (3). Supposing to generate these scenarios, a spatial 
data management software is required (1). In this research it was used QGIS, since it is opensource. Moreover, it is also a suitable software for generating routes, thanks to several plugins such as pgRouting, OSM Tools, v.net.distance. In order to use these tools, it is necessary to define an Origins - Destinations matrix (4). From the security side, the Civil Protection situation room or operations centre can be used as origins; while, the destination may be a safe place (e.g. a strategic building). As further hypothesis, for each O-D pair, if there are $n$ bridges, there must be $n$ paths (5). This on the one hand limits the model, but on the other hand greatly simplifies the calculations without losing accuracy. In fact, if all the crossing path of a river are considered, the method is correct. If there are more rivers placed in parallel, it will be necessary to break down the problem into several sub-problems. When simulating the collapse of a bridge and the consequent closure of the road, it is necessary to appraise the best alternative route in terms of travel time (8). This is feasible considering each of the alternative paths, and subsequently evaluate the increased volume caused by the interrupted road (6). Then, it is possible to derive the link traversal time using the HCM (7). Costs will be calculated only on the shorter alternative route. At the end of the procedure, for each element at risk and a single O-D pair, a Risk Index (RI) is assigned. RI is defined according to Equation (5).

$$
R I=(\$ H D+\$ H I) / \$ N H
$$

Where, \$HD are the direct costs; \$HI the indirect costs; \$NH the costs with no hazard (normal condition). All the costs are evaluated as reported in the next paragraph.

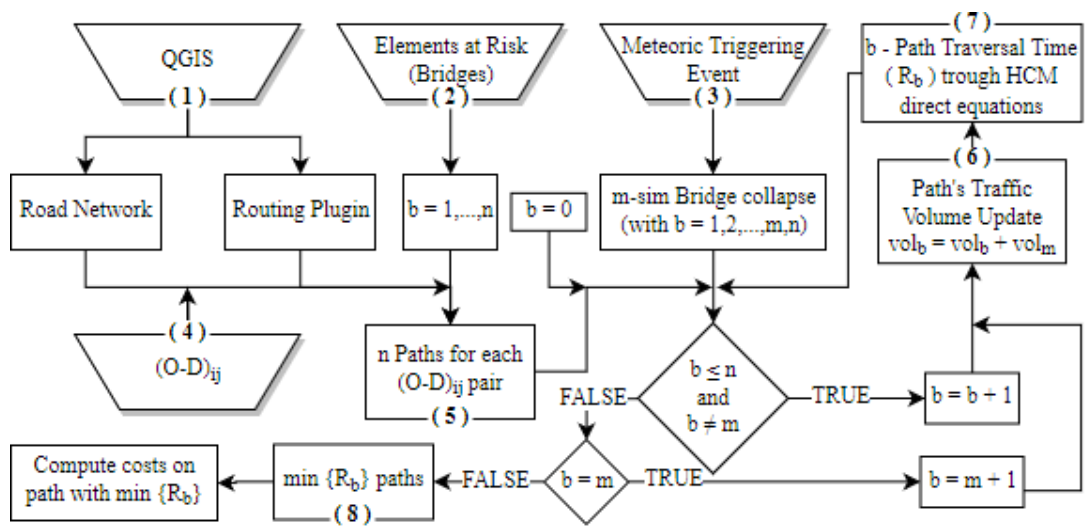

Fig. 3. Collapse scenarios flowchart.

\subsection{Costs}

The assessment of direct and indirect costs that follows a road closure, depends primarily on the element at risk. If the vulnerable spot is the bridge, the parameters involved in costs computation are considerably different than the ones referred e.g. to landslides. So, the procedure described varies depending on the road's closure reason. Assuming bridges as elements at risk, direct and indirect costs are assessed separately. Beyond that, a first division is necessary, because within each scenario caused by an extreme event, there are three possible consequences: (1) no consequences; (2) bridge damaged but fully functional; (3) bridge not functional or collapsed. For scenario (1) no cost assessment is required since there are no consequences. Regarding (2), direct costs concern: (A2) quantify the damage of structural and non-structural components; (B2) repairing costs. About (B2), the damages 
depend on the triggering event (e.g. a flood will produce different damages than a volcano eruption) and must be evaluated case by case. The common element is (A2) calculation. Concerning the scenario (3), the direct costs are: (A3) the elimination of debris; (B3) the bridge reconstruction. In particular, the expenses involved are: the cost of material acquisition and transportation, the cost of man-power and the equipment's cost. These vary from bridge to bridge because of some variables as, the construction site, the bridge type and material. For scenarios (2) and (3), indirect costs can be assessed using the same formula, but considering the difference in time to build a new bridge and to repair the existing one. The damage is measured in driver's delay cost due to the alternative path length and traffic congestion. With the same approach, vehicle's operational costs are assessed. Accident costs, noise and aesthetics costs are not included in this research. The costs are evaluated according to [19]. The driver's delay cost is calculated in Equation (6).

$$
D D C=\left(L / S_{a}-L / S_{n}\right) \times 1 \text { day } \times A D T \times \Sigma_{i}\left(D T C_{i} \times p_{i}\right)
$$

Where, $\mathrm{S}_{\mathrm{a}}(\mathrm{km} / \mathrm{h})$ is the traffic speed during the work activity; $\mathrm{S}_{\mathrm{n}}$ has the same meaning but during normal conditions; ADT (veh/day) is the average daily traffic; $p_{i}$ is the percentage of i-class vehicle; $\mathrm{DTC}_{\mathrm{i}}$ is the driver time cost per hour, for i-class vehicle. The latter parameter is calculated on the average hourly salary per person, for i-class vehicle, multiplied for the vehicle's rate of occupation. If the bridge collapses, the ADT must consider also the volume of traffic detoured from the closed road. Finally, $\mathrm{L}$ is the length of the motorway affected by the increased traffic volume. In addition, a vehicle shifted to another path, is subject to costs related to the consumption of fuel $\left(\mathrm{cf}_{\mathrm{i}}\right)$, tires $\left(\mathrm{ct}_{\mathrm{i}}\right)$, maintenance $\left(\mathrm{cm}_{\mathrm{i}}\right)$, depreciation $\left(\mathrm{cd}_{\mathrm{i}}\right)$. All these costs are expressed in Eur/km or, more generally: country currency / unit of length.

$$
V O C_{i}=c f_{i}+c t_{i}+c m_{i}+c d_{i}
$$

Where, $\mathrm{VOC}_{\mathrm{i}}$ is the vehicle's operational costs. Then the total cost is evaluated through Equation (8).

$$
V O C_{t o t}=\left(L-S_{a} / S_{n} \times L\right) \times 1 \text { day } \times A D T \times \Sigma_{i}\left(D T C_{i} \times p_{i}\right)
$$

Each scenario must be calibrated to the local average salary and traffic composition.

\section{Conclusions}

The research made in this work presents an innovative approach for road safety evaluation, in case of extreme weather events. The procedure shows the capability to extract the traffic data without on-site survey campaigns. The use of GIS software allows an integrated management of many spatial data. Moreover, the benefit from the routing plugins in the path finding considerably simplifies the entire framework. Finally, the evaluation of indirect costs is immediately assessable.

A further innovation concerns also the importance given to a bridge, based on the consequences that its collapse may have on the population. The method can help local stakeholders to draw up a list of infrastructures maintenance [20], [21] priorities, and to plan road closures without generating traffic congestions. But most importantly, the method can evaluate the operability and accessibility of emergency vehicles to villages and safe places within a specific damage scenario. By a parallel study about the hydraulic vulnerability of bridges' safety towards floods, the method can help the Civil Protection in the emergency's management and forecast. 


\section{References}

[1] L. Giresini, M. L. Puppio, and M. Sassu, 'Collapse of corrugated metal culvert in Northern Sardinia: analysis and numerical simulations', Spec. Issue Int. J. Forensic Eng., vol. 3, no. 1-2, 2016.

[2] A. Erath, J. Birdsall, K. W. Axhausen, and R. Hajdin, 'Vulnerability Assessment Methodology for Swiss Road Network'.

[3] K. Berdica and L. Mattsson, '5 Vulnerability : A Model-Based Case Study of the Road Network in Stockholm', 2002.

[4] G. M. Calvi et al., 'Once upon a Time in Italy: The Tale of the Morandi Bridge Once upon a Time in Italy: The Tale of the Morandi Bridge', vol. 8664, 2018.

[5] R. Morandi, 'The long-term behaviour of viaducts subjected to heavy traffic and situated in an aggressive environment: the viaduct on the Polcevera in Genoa', IABSE reports Work. Comm., pp. 170-180, 2018.

[6] ISFORT-CONFTRASPORTO, 'Valutazione del danno economico per il trasporto stradale', 2018.

[7] Comune di Genova, 'Pronto il cantiere per la demolizione del ponte Morandi', 2018. .

[8] Ferrovie dello Stato Italiane, 'Gruppo FS italiane: prosegue l'impegno per la Liguria', Genova, 2018.

[9] L. Giresini, S. Pagliara, M. Palermo, and M. Sassu, 'Collasso per sormonto idraulico di piccolo ponti in recenti alluvioni nella Toscana meridionale Collasso per sormonto idraulico di piccolo ponti in recenti alluvioni nella Toscana meridionale', IF CRASC'15, no. August, 2015.

[10] M. L. Puppio and S. Novelli, 'The case of Livorno', Des. Civ. Environ. Eng., vol. 46, no. 2016, pp. 190-202, 2018.

[11] F. Bazzucchi, L. Restuccia, and G. A. Ferro, 'Considerations over the Italian road bridge infrastructure safety after the Polcevera viaduct collapse: past errors and future perspectives', vol. 46, pp. 400-421, 2018.

[12] H. Dikanski, B. Imam, and A. Hagen-Zanker, 'Effects of uncertain asset stock data on the assessment of climate change risks: A case study of bridge scour in the UK', Struct. Saf., vol. 71, pp. 1-12, 2018.

[13] Geofabrik, 'OpenSteet Map Data Extract'. .

[14] A. Graser, M. Straub, and M. Dragaschnig, 'Towards an Open Source Analysis Toolbox for Street Network Comparison : Indicators, Tools and Results of a Comparison of OSM and the Official Austrian Reference Graph', vol. 18, no. 4, pp. 510-526, 2014.

[15] A. Chen, 'Capacity reliability of a road network : an assessment methodology and numerical results', vol. 36, 2002.

[16] TRB, Highway Capacity Manual. 2010.

[17] W. Rasband, 'ImageJ Official Website'. .

[18] J. P. Snyder, 'Map Projections - A Working Manual - USGS 1395', 1987.

[19] H. M. Gervásio, 'Sustainable design and integral life - cycle analysis of bridges', Universidade de Coimbra, 2010.

[20] F. Stochino, M. L. Fadda, and F. Mistretta, 'Assessment of RC Bridges integrity by means of low-cost investigations', no. October, 2018.

[21] F. Stochino, M. L. Fadda, and F. Mistretta, 'Low cost condition assessment method for existing RC bridges Low Cost condition assessment method for existing RC bridges', no. December, 2017. 